\title{
Effect of Grapefruit Juice on
}

Aluminum-Induced Hepatotoxicity in

Albino Rats: Histological, Ultrastructural and Histochemical Assessment

\author{
Wael M. Al-Amoudi \\ Department of Biology, Faculty of Applied Sciences, Umm Al-Qura University, Makkah, KSA \\ Email:wmamoudi@uqu.edu.sa
}

How to cite this paper: Al-Amoudi, W.M. (2017) Effect of Grapefruit Juice on Aluminum-Induced Hepatotoxicity in Albino Rats: Histological, Ultrastructural and Histochemical Assessment. Advances in Bioscience and Biotechnology, 8, 463-477. https://doi.org/10.4236/abb.2017.812034

Received: November 7, 2017

Accepted: December 5, 2017

Published: December 8, 2017

Copyright $\odot 2017$ by author and Scientific Research Publishing Inc. This work is licensed under the Creative Commons Attribution International License (CC BY 4.0).

http://creativecommons.org/licenses/by/4.0/

\begin{abstract}
The present work studied the effect of grapefruit juice (Citrus) on the hepatotoxicity of $\mathrm{AlCl}_{3}$. Four groups of adult male albino rats were used. Group I contained 10 rats and remained as a control group; Group II: 10 rats were included and orally administered with grapefruit juice at a dose level of 27 $\mathrm{ml} / \mathrm{kg}$ of body weight per day for 6 weeks; Group III: 10 rats were included and $\mathrm{AlCl}_{3}$ was administered orally at a dose level of $100 \mathrm{mg} / \mathrm{kg}$ of body weight per day for 6 weeks; Group IV: animals of this group (10 rats) were given a combination of $\mathrm{AlCl}_{3}$ and grapefruit juice per day for 6 weeks. At the end of the sixth week, the liver was processed for histological and ultrastructure studies. In addition, ALT and AST were determined in blood sera. The results showed that $\mathrm{AlCl}_{3}$ induced several histological alterations in the liver, including congestion of blood vessels, leucocytic infiltration, cytoplasmic vacuolation of hepatocytes and fatty infiltrations. Ultrastructural changes include the degeneration of mitochondria, RER swelling and pyknosis of the nuclei with an increase in fat droplets and lysosomes. The biochemical results showed an increase in ALT and AST activities in the $\mathrm{AlCl}_{3}$ group. However, the group of rats treated with $\mathrm{AlCl}_{3}$ and grapefruit juice improved the histological and ultrastructural changes, while the levels of ALT and AST were reduced. It was concluded in the results that grapefruit juice has a protective effect against hepatotoxicity of $\mathrm{AlCl}_{3}$ that can be attributed to the antioxidant properties of its components.
\end{abstract}

\section{Keywords}

$\mathrm{ALCl}_{3}, \mathrm{Grapefruit}$ Juice, Hepatotoxicity, Histology, Transaminases, Rats 


\section{Introduction}

Humans are exposed to toxic metals through water, polluted air, food, and soil. Aluminum ( $\mathrm{AL}$ ) is the third most common element in the earth's crust and is omnipresent in the environment [1]. Aluminum is a component of cooking utensils, medicines such as antacids, deodorants, perspirants, food additives, packaging foil, drying agent (for example, Sodium aluminosilicate-a fine powder), used to dry cocoa, salt and other products, a flocculant agent in the most municipal water supply [2]. In addition, it can be found in foods, especially corn, yellow cheese, salt, herbs, spices and tea [3]. The target tissues for loading aluminum are bone, brain, kidney, and liver. The signs and symptoms of Al toxicity include: neurodegenerative diseases [4], hematological abnormalities [5] and liver damage [6]. It also caused oxidative stress and an increase in lipid peroxidation [7].

The importance of medicinal plants and traditional health systems to solve the problems of health care in the world is gaining more and more attention. Grapefruit is a citrus subtropical plant that contains many nutrients and phytochemicals, capable of contributing to a healthy diet [8]. Grapefruit showed different medicinal uses. Grapefruit seed extract (GSE) showed strong antimicrobial properties [9] and reduced cholesterol levels [10]. It has been demonstrated the anticancer properties of orange juice and indicated that citrus flavonoids are effective inhibitors of human breast cancer cell proliferation in vitro [11] [12]. Grapefruit juice intake suppresses Aflatoxins B1 (AFB1) induced liver DNA damage in rats [13]. [14] reported that grapefruit prevents cytogenetic and testicular damage induced by rytmonorm in rats. The objective of this work is to study the effect of grapefruit in aluminum hepatotoxicity in albino rats.

\section{Materials and Methods}

\subsection{Animals and Treatments}

Healthy adult male albino rats (Rattusnorvegicus), about three months old and each weighing $150 \pm 5 \mathrm{~g}$, were used in the study. They were obtained from King Abdul-Aziz University, King Fahad Medical Research Center, Jeddah, Saudi Arabia. The animals were kept in plastic cages with the control of room temperature $\left(25^{\circ} \mathrm{C} \pm 2{ }^{\circ} \mathrm{C}\right)$, humidity $(55 \% \pm 5 \%)$ and light $(12: 12$ dark hours/light cycles). All animals were given standard feed (commonly used pelleted diet) and tap water ad libitum. They were adapted for a week before the experiment to acclimatize them to laboratory conditions. The animals were conducted in accordance with the Institutional Guidelines for the care and use of experimental animals. The rats were randomly divided into four groups; each group contained 10 animals as follows:

Group I: Animals served as controls.

Group II: Rats were orally administered with grapefruit juice (Citrus paradise) at a dose level of $27 \mathrm{ml} / \mathrm{kg}$ body weight daily for 6 weeks [14]. Grapefruit (Citrus paradise) used in the work was purchased from local markets in Jeddah 
city, Saudi Arabia. Juice of grapefruit was prepared by squeezing the fresh fruit.

Group III: Animals of this group were orally given $\mathrm{ALCl}_{3}$ at a dose level of $100 \mathrm{mg} / \mathrm{kg}$ bw daily for 6 weeks [15].

Group IV: Animals of this group were given $\mathrm{ALCl}_{3}(100 \mathrm{mg} / \mathrm{kg}$ b.w.) followed by grapefruit juice ( $27 \mathrm{ml} / \mathrm{kg}$ b.w.) daily for 6 weeks.

\subsection{Histological and Histochemical Studies}

For the histological study, the animals were sacrificed after 6 weeks; the liver was immediately removed and fixed in $10 \%$ neutral formalin for 24 hours. After fixation, the specimens were dehydrated in ascending series of ethyl alcohol, rinsed in two xylene changes, infiltrated in three changes of molten paraffin wax with a melting point of $58^{\circ} \mathrm{C}-60^{\circ} \mathrm{C}$ and then embedded in molten paraffin blocks. The 5 micron thick sections were cut using a rotary microtome and mounted on clean slides. For histological examination, the sections were stained with Ehrlich's hematoxylin and counterstained with Eosin.

The periodic acid Schiff (PAS) technique was used for the histochemical demonstration of total carbohydrates [16]. Total proteins were detected using the bromphenol mercury blue method [17] and DNA was detected using the Feulgen reaction [16].

\subsection{Electron Microscopy}

For electron microscopy, small pieces of liver were fixed in $2.5 \%$ glutaraldehyde in $0.1 \mathrm{M}$ cacodylate buffer at $\mathrm{pH}$ 7.4. The samples were washed in $0.1 \mathrm{M}$ phosphate buffer at $4^{\circ} \mathrm{C}$, and then post-fixed in $1 \%$ osmium tetroxide for 2 hours at $4^{\circ} \mathrm{C}$. The samples were dehydrated in ascending degrees of ethyl alcohol and then placed in propylene oxide and embedded in Epon resin. Semitine sections $(1 \mu \mathrm{m})$ were stained with toluidine blue in borax and examined with a light microscope. Ultrathin sections $(40 \mathrm{~nm})$ were cut, mounted on copper grids and stained with uranyl acetate and lead citrate [18]. The sections were examined and photographed with the transmission electron microscope Jeol 1200 EX.

\subsection{Biochemical Assays}

For biochemical analysis, blood samples were taken after 6 weeks of treatment in clean centrifuge tubes $(n=5)$. The blood samples were allowed to coagulate at room temperature and then the serum was separated by centrifugation at 3000 $\mathrm{rpm}$ for 20 minutes. The collected serum is stored at $18^{\circ} \mathrm{C}-20^{\circ} \mathrm{C}$ until analysis. The activities of alanine aminotransferase (ALT) and aspartate aminotransferase (AST) were estimated according to the method of [11].

\subsection{Statistical Analysis}

Data were expressed as mean \pm SEM. The analysis was carried out using the Statistical Package for Social Sciences (software SPSS version 16). Student's t-test was performed to evaluate the importance of the differences between the groups. 
The significance at $P<0.05$ was considered statistically significant. When ANOVA resulted in differences, multiple comparisons between means were studied by the Tukey-Kramer test.

\section{Results}

\subsection{Change in Total Body Weight}

Animals treated with $\mathrm{AlCl}_{3}$ for 6 weeks showed a significant decrease in body weight compared to the control group (Figure 1). On the other hand, the rats that received $\mathrm{AlCl}_{3}$ and grapefruit showed a significant increase in the body weight of the rats compared to the $\mathrm{AlCl}_{3}$ group. There were no significant differences in the body weight of the control animals and those who received grapefruit (Figure 1).

\subsection{Histological Results}

Liver examination of control rats stained with $\mathrm{H} \& \mathrm{E}$ revealed liver cells arranged in plates radiating from the central vein; with hepatic sinusoids and Kupffer cells (Figure 2(a)). Liver sections of rats given grapefruit showed a normal histological structure (Figure 2(b)). The liver of rats treated with ALCI3 for 6 weeks revealed a congestion of the central and portal veins (Figure 2(c)), in the same specimen, inflammatory cell infiltration, and bile duct enlargement was observed (Figure 2(d)). In addition, the hepatic architecture of the $\mathrm{AlCl}_{3}$ group was lost and the hepatocytes appeared with cytoplasmic vacuolization and pyknotic nuclei (Figure 3(a)). Leukocytic infiltration masses and congested blood vessels were still observed. Fat infiltration of fat droplets of different sizes was also observed (Figure 3(b)). The examination of rat liver treated with $\mathrm{AlCl}_{3}$ and grapefruit showed normal hepatocytes with normal nuclei around the central vein with normal sinusoids with activated kupffer cells and a minimum number of inflammatory leukocytes (Figure 3(c)).

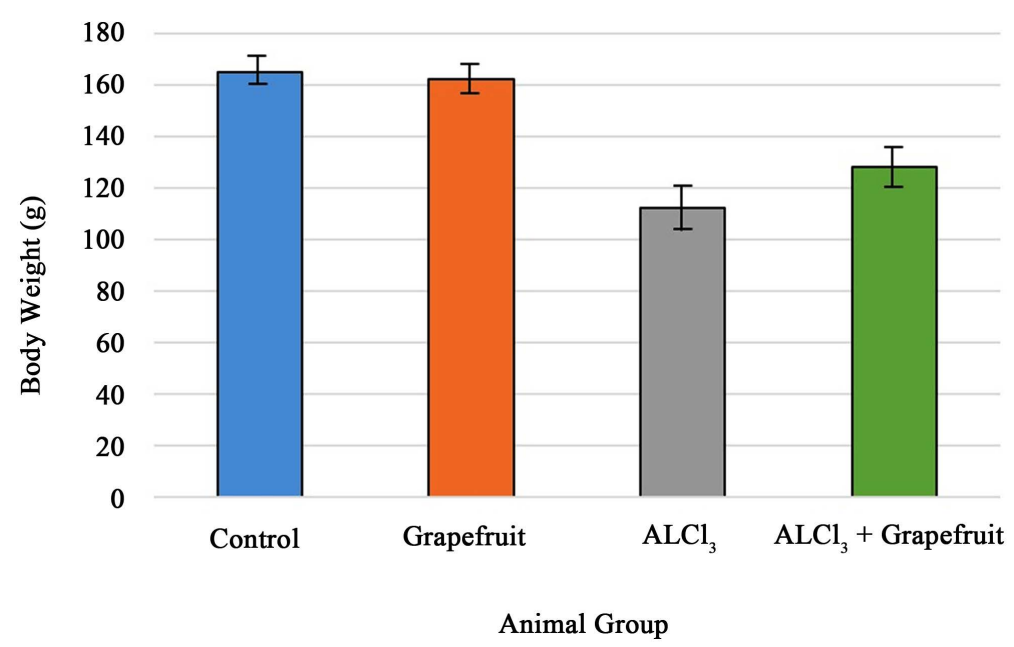

Figure 1. Body weights of male rats treated with $\mathrm{ALCl}_{3}$, grapefruit and their combination. The results are expressed as mean $\pm \mathrm{SEM}, n=5$ mice/group. 


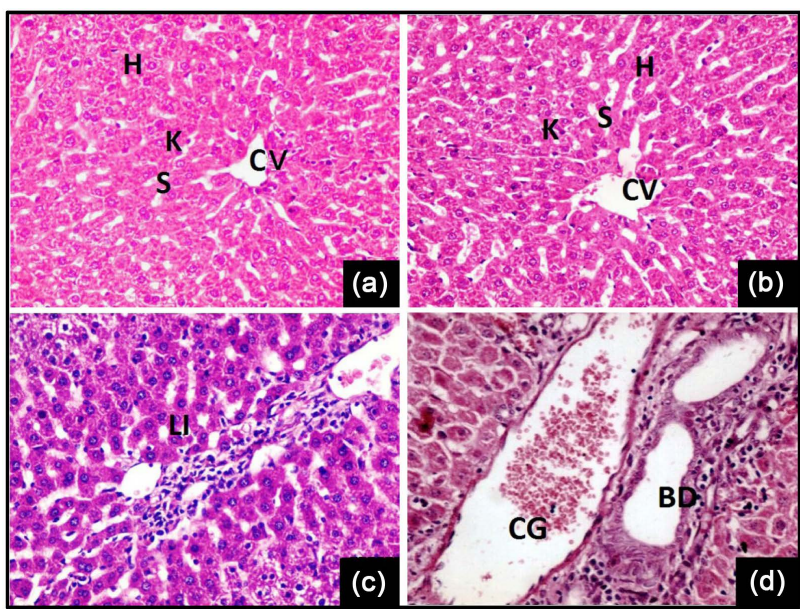

Figure 2. (a) Section in the liver of a control rat showing central vein (CV), Sinusoidal space (S) with kupffer cell $(\mathrm{K})$ and hepatocyte $(\mathrm{H}), \times 400$; (b) The section in the liver of a rat treated with grapefruit showing the normal architecture of hepatocyte $(\mathrm{H})$, Sinusoids $(\mathrm{S})$, Kupffer cell $(\mathrm{K})$ and central vein $(\mathrm{CV}), \times 400$; (c) Liver section of a rat treated with $\mathrm{ALCl}_{3}$ showing leucocytic infiltrations (LI), $\times 400$; (d) Liver section of a rat treated with $\mathrm{ALCl}_{3}$ showing congested and enlarged portal vein (CG) and enlarged bile duct (BD), $\times 400$.

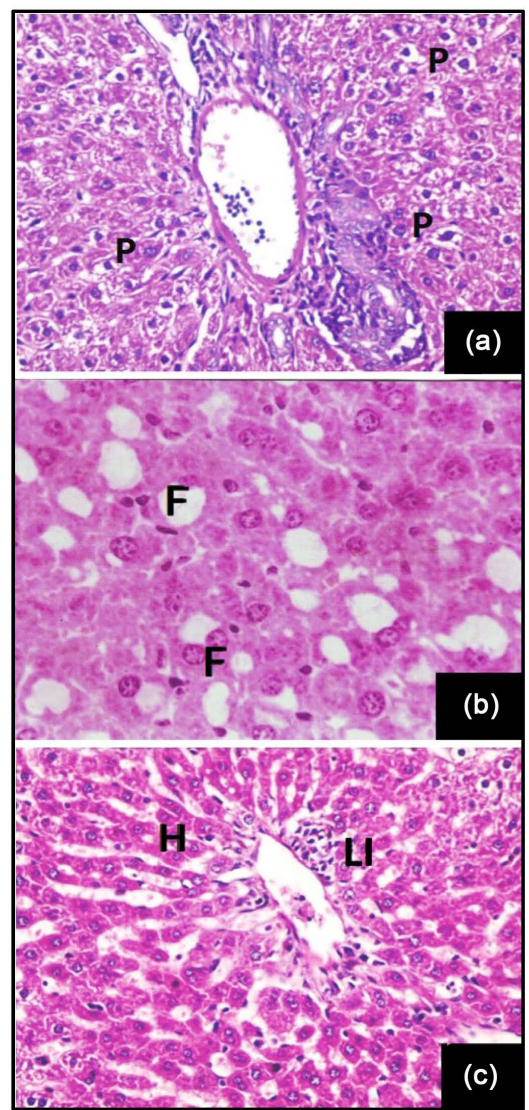

Figure 3. (a) Hepatocytes of $\mathrm{AlCl}_{3}$-treated rat showing cytoplasmic vacuolation with pyknotic nuclei (P), $\times 400$; (b) Fatty infiltration (F), $\times 400 \mathrm{C}$. The section in the liver of a rat treated with $\mathrm{ALCl}_{3}$ and grapefruit showing improvement in hepatic tissue $(\mathrm{H})$ with few leucocytic infiltrations (LI), $\times 400$. 


\subsection{Histochemical Results}

\subsubsection{Total Carbohydrates}

Examination of the liver section of a control rat and those that were given grapefruit showed that the hepatocytes contain pink granules of a strong PAS reaction in the pole of the cytoplasm of hepatocytes (glycogen flight) while nuclei exhibited negative stain (Figure 4(a) and Figure 4(b)). Examination of the liver of rats treated with $\mathrm{ALCl}_{3}$ for 6 weeks showed a decrease of the glycogen content (Figure 4(c)). However, rats given $\mathrm{ALCl}_{3}$ and grapefruit for 6 weeks revealed an increase in the carbohydrate content (Figure 4(d)).

\subsubsection{Total Proteins}

Liver of a control rat and rats given grapefruit showed normal protein content in the hepatocytes as dense blue granules in the cytoplasm, cell membrane, nuclear membrane, chromatin bodies, nucleoli and Kupffer cells (Figure 5(a) and Figure 5(b)). Liver sections of rats treated with $\mathrm{ALCl}_{3}$ for 6 weeks showed a marked reduction of the protein content (Figure 5(c)), while rats treated with $\mathrm{ALCl}_{3}$ and grapefruit revealed improvement in the protein content (Figure 5(d)).

\subsubsection{DNA}

Liver of control rats and animals that were given grapefruit revealed that the DNA-containing particles (chromatin) appeared in the form of densely stained red particles distributed in the nucleoplasm and the peripheral rim of the nuclei of hepatocytes of control rats (Figure 6(a) and Figure 6(b)). Hepatic cells of rats treated with $\mathrm{ALCl}_{3}$ showed that most nuclei exhibited a weak Feulgen reaction of their chromatin granules (Figure 6(c)). Rats treated with $\mathrm{ALCl}_{3}$ and grapefruit for 6 weeks showed that most of the nuclei appeared with a normal amount of DNA-containing particles (Figure 6(d)).

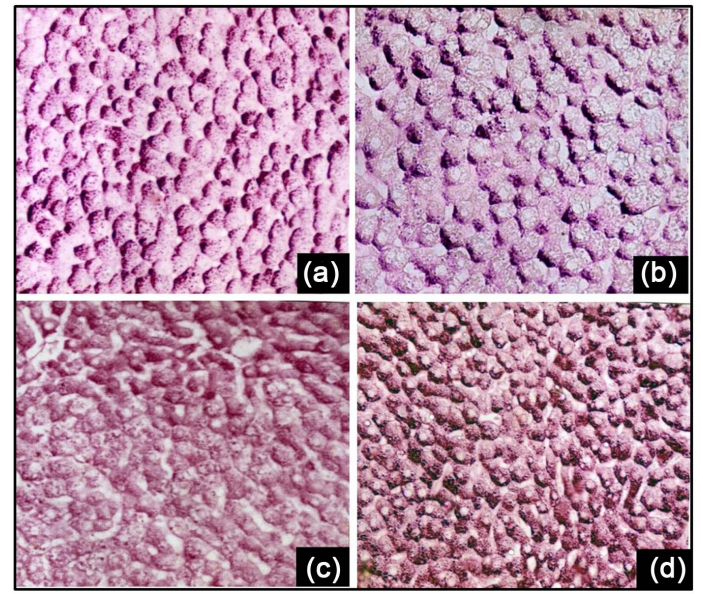

Figure 4. (a) Liver section of a control rat showing PAS positive materials in the cytoplasm of the cells. The nuclei gave a negative reaction; (b) The section in the liver of a rat given grapefruit showing normal distribution of carbohydrates; (c) Section of the liver of a rat treated with $\mathrm{ALCl}_{3}$ showing weak PAS reaction in a large number of hepatocytes; (d) An increase in carbohydrates content in hepatocytes of a rat given $\mathrm{ALCl}_{3}$ and grapefruit (PAS, $\times 400)$. 


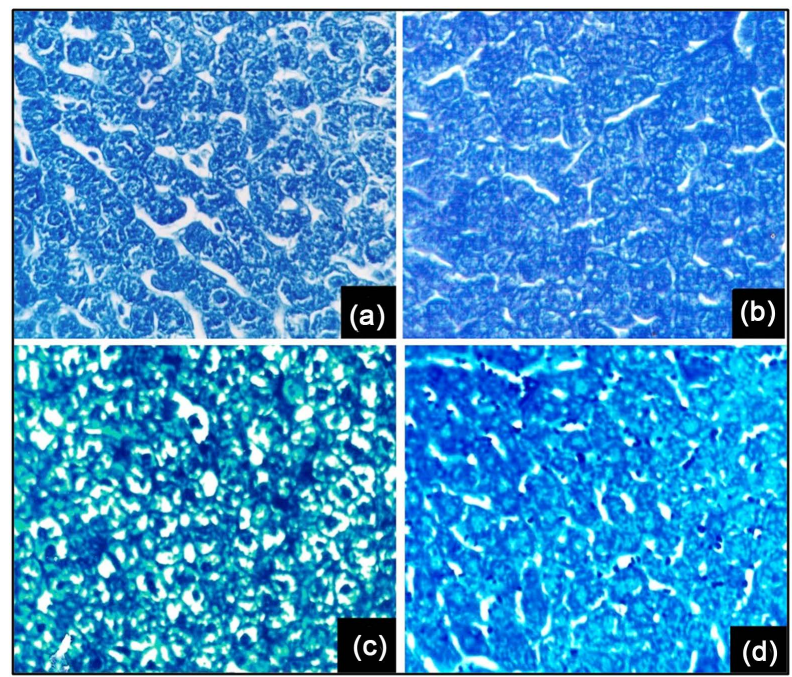

Figure 5. (a) Normal protein content in the hepatocytes of a control rat appears as dense bluish bodies in the cytoplasm; (b) Normal distribution of total hepatocytes of a rat given grapefruit; (c) Reduction of the protein content in the hepatic cells of a rat given $\mathrm{ALCl}_{3}$; (d) Restoration of total protein content in hepatic cells of a rat treated with $\mathrm{ALCl}_{3}$ and grapefruit (Mercury bromophenol blue, $\times 400$ ).

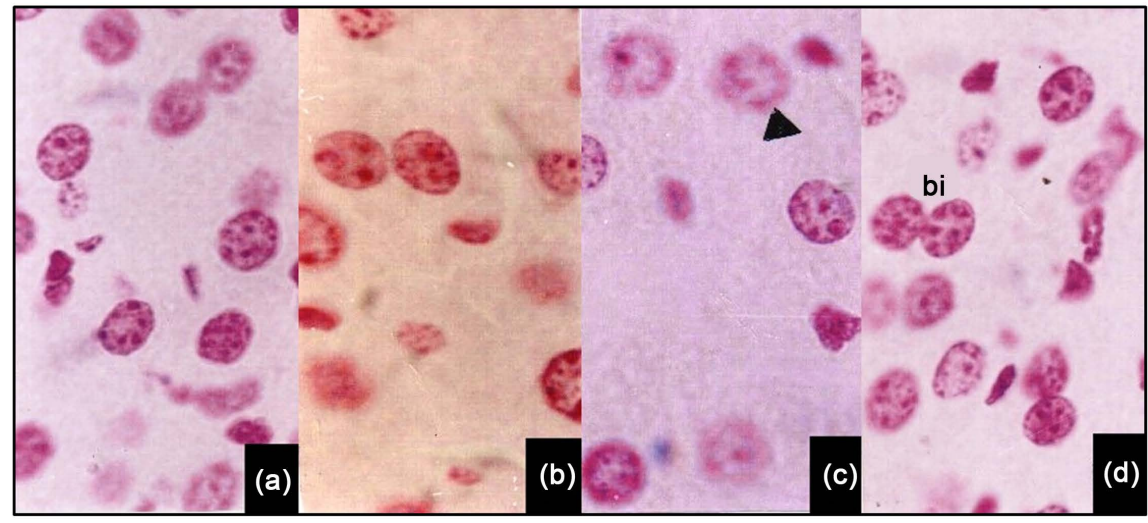

Figure 6. (a) DNA-containing particles in the nuclei of hepatic cells of a control rat; (b) Nuclei of hepatocytes of a rat given grapefruit showing the normal content of DNA; (c) Reduction of DNA-containing particles in the nuclei of hepatic cells of an animal treated with $\mathrm{ALCl}_{3}$ (arrowhead); (d) Nuclei of hepatocytes of a rat treated with $\mathrm{ALCl}_{3}$ and grapefruit showing restoration of DNA content, (bi) binucleated cell (Feulgen reaction $\times 1000$ ).

\subsubsection{Ultrastructure Results}

Ultrastructural examination of the liver of control rat revealed that the hepatocytes appeared with a normal nucleus, with the obvious nucleolus. The chromatin is allocated to heterochromatin and euchromatin. The cytoplasm contains numerous various sized-oval and elongated mitochondria, numerous cisternae of rough endoplasmic reticulum (Figure $7(a)$ ). In addition, the bile canaliculi located throughout the hepatocytes with normal microvilli. On the other hands, rats treated with $\mathrm{ALCl}_{3}$ for 6 weeks showed various deteriorations. The bile canaliculi appeared with destructed microvilli and the cytoplasm was ratified with disrupted rough endoplasmic reticulum (Figure 7(b)). Mitochondria appeared 

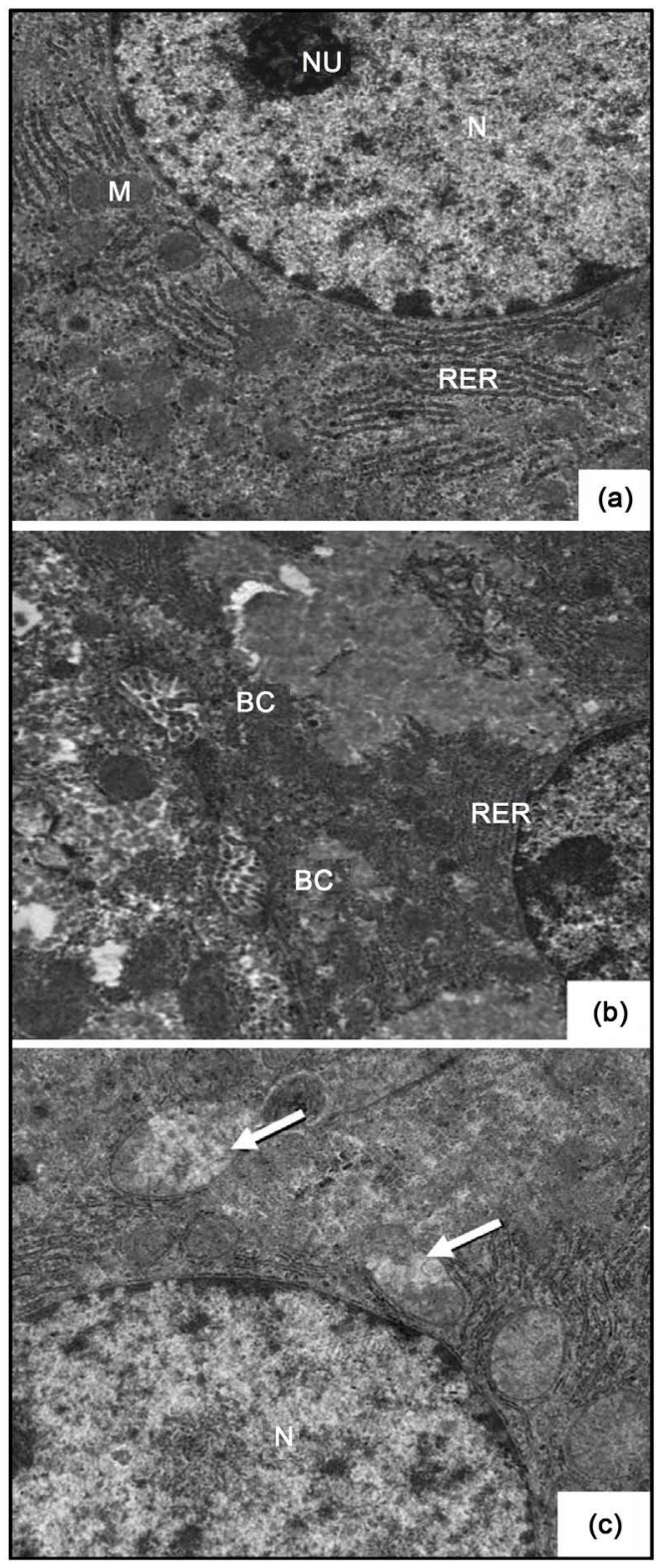

Figure 7. TEM micrograph showing, (a) Hepatocyte of a control rat showing nucleus (N), nucleolus (NU), regular mitochondria (M) and rough endoplasmic reticulum (RER); (b) Liver from a rat treated with $\mathrm{ALCl}_{3}$ showing ratified cytoplasm, bile canaliculi with fragmented microvilli (BC) and disrupted RER; (c) Swollen mitochondria (arrows) with destructed cristae $(\times 5000)$.

swollen with destructed cristae (Figure 7(c)). Moreover, rat treated with $\mathrm{AlCl}_{3}$ showed degenerated nuclei and showed irregular nucleus, vacuoles and fat droplets of different sizes were encountered (Figure 8(a)). A large number of lysosomes were observed (Figure 8(b)). After treatment with $\mathrm{AlCl}_{3}$ and grapefruit, most of the hepatocytes appeared with normal nuclei and normal organelles (Figure $8(c)$ ). However, rat treated with grapefruit showed normal nucleus with a large number of healthy mitochondria and rough endoplasmic reticulum and lysosome. 

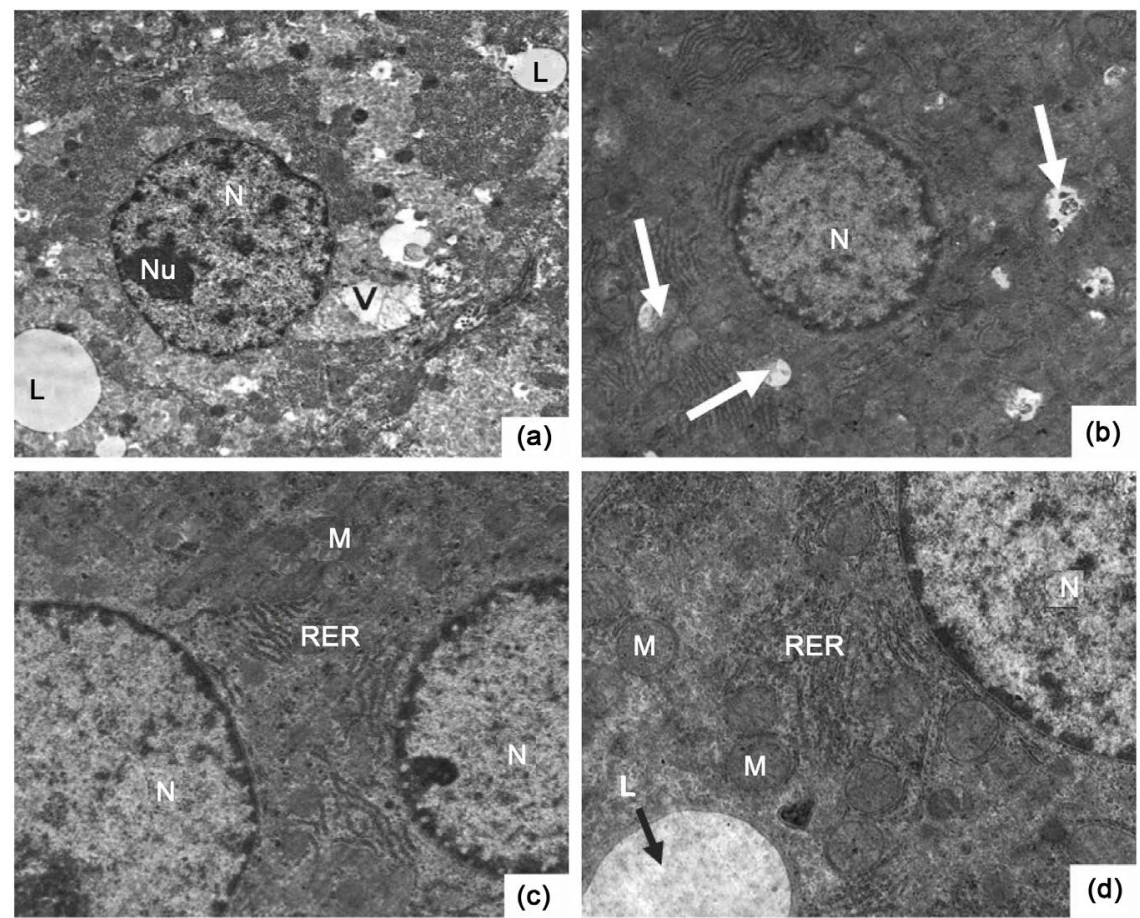

Figure 8. (a) Liver of $\mathrm{ALCl}_{3}$ treated rat showing nucleus with irregular membrane, vacuoles (V) and Lipid droplets (L); (b) A large number of lysosomes; (c) Liver of a rat treated with $\mathrm{AlCl}_{3}$ and grapefruit showing normal nuclei $(\mathrm{N})$, mitochondria $(\mathrm{M})$ and rough endoplasmic reticulum $(\mathrm{RER}), \times 5000$; (d) Liver of rat treated with grapefruit showing normal nucleus $(\mathrm{N})$ with the regular membrane, mitochondria $(\mathrm{M})$ and RER.

\subsubsection{Biochemical Results}

Treating animals with $\mathrm{ALCl}_{3}$ for 6 weeks induced an increase $(P<0.05)$ in the level of ALT and AST when compared with those of the control animals. These enzymes were restored to close ordinary qualities in rats treated $\mathrm{ALCl}_{3}$ and grapefruit. There were no significant differences in the levels of these two enzymes between control and rats given grapefruit (Figure 9 \& Figure 10).

\section{Discussion}

Results obtained in the present study revealed that $\mathrm{AlCl}_{3}$ caused a significant decrease in the body weight of rats. In agreement with this result, [19] found out that excessive $\mathrm{AlCl}_{3}$ exposure led to a reduction in body relative liver weights. In addition, [3] and [20] have also reported that $\mathrm{AlCl}_{3}$ have significantly caused remarkable changes in the total body weight, absolute and relative liver weights of rats. The authors concluded that this reduction could be as a result of feed consumption and/or malabsorption of nutrients induced by $\mathrm{AlCl}_{3}$ exposure, which has an effect on the gastrointestinal tract and/or inhibition of protein synthesis.

$\mathrm{AlCl}_{3}$ has been reported to induce histological and ultrastructural alterations in the hepatic tissue of rats. Similarly, [21] reported that treating rats with a high dose of $\mathrm{AlCl}_{3}$ led to some histological changes which include: microvascular fatty, Kupffer cell hyperplasia as well as multiplication of bile canalicules. Other 


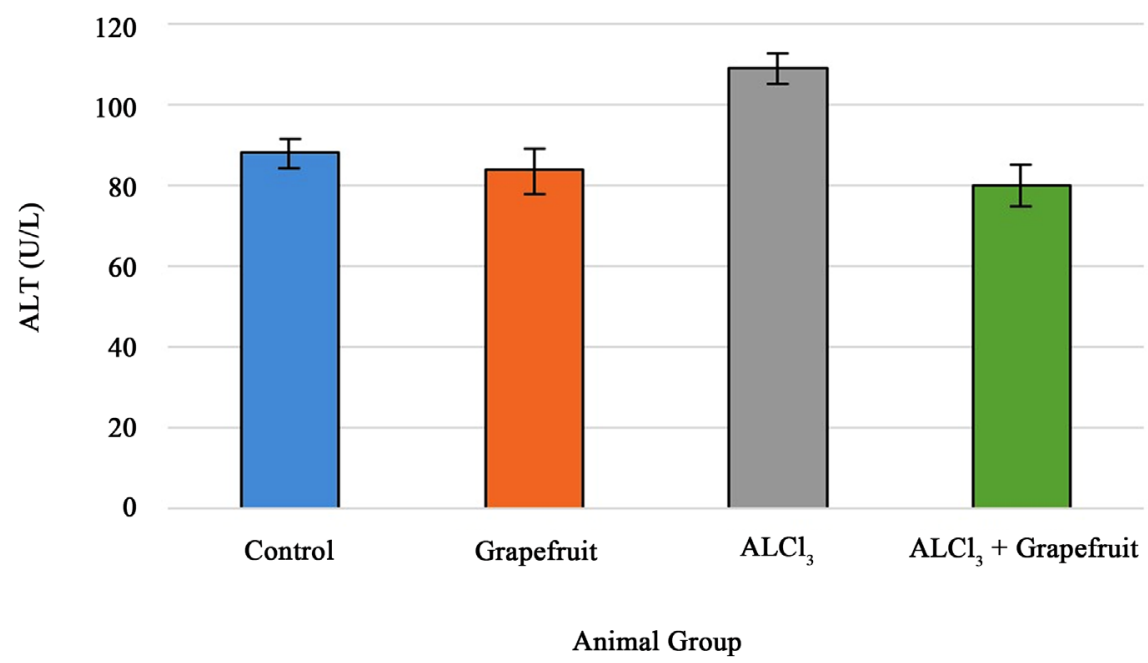

Figure 9. Effect of $\mathrm{ALCl}_{3}$ and Grapefruit on alanine aminotransferase $(A L T)$ level (U/L) of male rats. The group treated with $\mathrm{ALCl}_{3}$ showed a significant increase in ALT activity compared with control and grapefruit groups. The group treated with $\mathrm{ALCl}_{3}$ and grapefruit showed a positive effect, leading to a reduction in the ALT activity compared to the $\mathrm{ALCl}_{3}$ treated group. The results are expressed as mean $\pm \mathrm{SEM}, n=5$ mice/group.

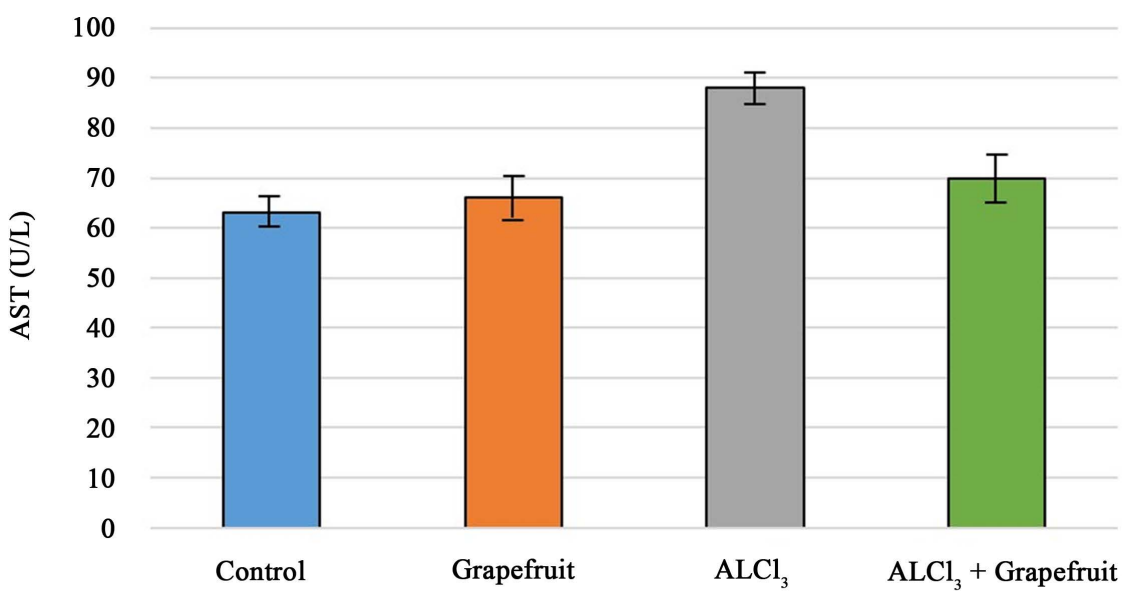

Animal Group

Figure 10. Effect of $\mathrm{ALCl}_{3}$ and Grapefruit on aspartate aminotransferase (AST) level (U/L) of male rats. The group treated with $\mathrm{ALCl}_{3}$ showed a significant increase in AST activity compared with control and grapefruit groups. The group treated with $\mathrm{ALCl}_{3}$ and grapefruit showed a positive effect, leading to a reduction in the AST activity compared to the $\mathrm{ALCl}_{3}$ treated group. The results are expressed as mean $\pm \mathrm{SEM}, n=5$ mice/group.

studies indicated that intoxicated animals with $\mathrm{AlCl}_{3}$ caused different histopathological changes in the liver of the rat. It also showed some histopathological alteration in other organs such as brain and kidney [22] [23] [24]. In addition, the results of this study showed a significant increase in the liver enzymes level of ALT and AST of rats group treated with $\mathrm{AlCl}_{3}$. These results confirmed that $\mathrm{AlCl}_{3}$ has caused liver injury and disrupted the normal enzyme function. These changes are similar to other results reported by [19] [25] [26]. 
Histochemical results showed noticeable depletion of carbohydrates, proteins, and DNA in hepatocytes of $\mathrm{AlCl}_{3}$-intoxicated rats. In this concern, [27] observed a decrease in the glycogen level in both liver and brain of the rat as a result of aluminum phosphide treatment, which was accompanied by a noticed increase in glycogen phosphorylase activity in both tissues. Protein content was also decreased in liver of rats intoxicated with a high dose of $\mathrm{AlCl}_{3}$. [23] revealed a significant reduction in liver protein concentrations caused by aluminum compared to the control group. A similar result was reported by [28] who noticed a marked decrease in the serum of the liver and brain proteins during aluminum administration in rats. Some studies revealed that $\mathrm{AlCl}_{3}$ caused a severe damage to the hepatic DNA of rats. Moreover, it was reported that DNA damage in the cerebrum and cerebellum is a consequence effect caused by $\mathrm{AlCl}_{3}$ treatment [4] and hepatocytes [12] of rats. Aluminum had a genotoxic profile and has been shown to bind to DNA, leading to a remarkable damage [29]. These reported results are similar to the result shown in this study in which $\mathrm{AlCl}_{3}$ was found to be a toxic element leading to histopathological alterations as well as causing significant biochemical abnormality in hepatic enzymes activity, carbohydrates, protein, and DNA contents.

It was reported that different forms of aluminum element are toxic to the environmental [24]. It accumulates in different organs and tissue of the biological systems and provoke free radicals mediated causing abnormality in the bio-system and leads to health problems such as: cardiotoxicity, hepatotoxicity, nephrotoxicity, neurotoxicity and alterations in antioxidant enzymes activity in both vivo and in-vitro trails [26] [30] [31]. [25] and [32] reported that aluminum-induced changes in biochemical parameters increased lipid peroxidation and decreased the activities of the antioxidant enzymes in plasma and different animal. Thus, the hepatotoxicity of $\mathrm{AlCl}_{3}$ may be due to its generated oxidative stress.

In this present study co-administration of grapefruit attenuates the hepatotoxicity of $\mathrm{AlCl}_{3}$. Grapefruit (Citrus) caused an increase in body weight and illuminated the $\mathrm{AlCl}_{3}$ negative effect in the intoxicated rats. This may be due to an increase in food intake and/or grapefruit capability to interfere with the absorption of $\mathrm{AlCl}_{3}$ in the intestine [26]. Moreover, grapefruit administration improved the histological and ultrastructural structure of the liver and decreased ALT and AST activities. Citrus plants are a good source of flavonoids, naringin, naringenin, nobiletin, narirutin, and hesperidin are the most essential flavonoids found in citrus fruits [26]. These components were discovered to have strong antioxidant and anti-inflammatory activities both in vitro and in vivo and demonstrated to have potential health benefits [33]. Naringenin is one of the major components found in grapefruit, it was indicated to inhibit liver damage and fibrosis induced by dimethylnitrosamine (DMN) and restored ALT, AST and alkaline phosphatase (ALP) activity to the normal level [34]. Citrus unshiu extract has also been reported to ameliorate hepatic steatosis and hypertriglyceridemia by 
inhibiting the gene expression and increasing the activation of lipogenic enzymes and fatty acids oxidation in the liver [35]. An increase in hepatic carbohydrates, proteins and DNA was observed in rats given and $\mathrm{AlCl}_{3}$ plus grapefruit. These results are in line with the report of [36] and [37] who reported that grapefruit juice restores the renal contents of carbohydrates and proteins to normal contents. [13] reported that rats were given grapefruit juice prior to treatment with aflatoxin- $\mathrm{B}_{1}$ resulted in a noticeable reduction of DNA damage in the liver.

It was reported that the therapeutic effect of grapefruit is due to its radical scavenging property and antioxidant activity [38]. Grapefruit juice is commonly consumed in many countries for its nutritive value, as well as antigenotoxic and antioxidant effects [39]. [40] indicated that two bioactive compounds were isolated from grapefruit juice and grapefruit peel oil. The chemical structures of these compounds were identified as bergaptol and geranyl coumarin which was reported to have effective antioxidant properties. The bergaptol component showed very good radical scavenging activity at all the tested concentrations [40] [41]. Furthermore, an increase in MDA and a decrease in SOD, CAT, GPx level, induction of hepatocellular degeneration and steatosis were recorded in rats supplemented with a high-fat diet. On the other hand, these negative changes were improved in animals fed with grapefruit juice [41]. It has been stated that grapefruit juice reduced lipid peroxidation marker, MDA and increased GSH in Streptozotocin-induced diabetic rats [38]. [42] found that purple grape juice prevented the damage caused by carbon tetrachloride in tissues of rats and they attributed this prevention to the rich polyphenol content of grapes.

\section{Conclusion}

In conclusion, the result obtained from this investigation indicates that grapefruit juice provides cellular and hepatoprotection against hepatotoxicity induced by $\mathrm{AlCl}_{3}$. Grapefruit reduced the effect caused by $\mathrm{AlCl}_{3}$ of the ALT, AST, body weight and protected the normal amount of DNA-containing particles in the nuclei. In addition, the histological and morphological improvements of hepatocytes indicated that grapefruit juice has antioxidant properties.

\section{References}

[1] Santa, C., Alessandro, M., Nadia, F., Sebastiano, G., Gioacchino, C., Udo, S., and Michele, N. (2017) Anticancer Potential of Citrus Juices and Their Extracts: A Systematic Review of Both Preclinical and Clinical Studies. Frontiers in Pharmacology, 8, 420. https://doi.org/10.3389/fphar.2017.00420

[2] Kandiah, J. and Kies, C. (1994) Aluminum Concentration in Tissues of Rats: Effect of Soft Drink Packaging. Biometals, 7, 57-60. https://doi.org/10.1007/BF00205195

[3] El-Demerdash, F.M. (2004) Antioxidant Effect of Vitamin E and Selenium on Lipid Peroxidation, Enzyme Activities and Biochemical Parameters in Rats Exposed to Aluminum. Trace Elements in Medicine, 18, 113-121. https://doi.org/10.1016/j.jtemb.2004.04.001 
[4] Bhalla, P., Singla, N. and Dhawan, D.K. (2010) Potential of Lithium to Reduce Aluminum-Induced Cytotoxic Effects in Rat Brain. BioMetals, 23, 197-206. https://doi.org/10.1007/s10534-009-9278-4

[5] Lukyanenko, L.M., Skarabahatava, A.S., Slobozhanina, E.I., Kovaliova, S.A., Falcioni, M.L. and Falcioni, G. (2013) In Vitro Effect of $\mathrm{AlCl}_{3}$ on Human Erythrocytes: Changes in Membrane Morphology and Functionality. Journal of Trace Elements in Medicine and Biology, 27, 160-167. https://doi.org/10.1016/j.jtemb.2012.10.003

[6] Chinoy, N.J. and Patel, T.N. (1999) Reversible Toxicity of Fluoride and Aluminum in Liver and Gastrocnemius Muscle of Female Mice. Fluoride, 32, 215-229.

[7] Prakash, A and Kumar, A. (2009) Effect of N-Acetyl Cysteine against Aluminum-Induced Cognitive Dysfunction and Oxidative Damage in Rats. Basic \& Clinical Pharmacology \& Toxicology, 105, 98-104.

https://doi.org/10.1111/j.1742-7843.2009.00404.x

[8] Fellers, P.J., Nikdel, S. and Lee, H.S. (1990) Nutrient Content and Nutrition Labeling of Several Processed Florida Citrus Juice Products. Journal of the American Dietetic Association, 90, 1079-1084.

[9] Ganzera, M., Aberham, A. and Stuppner, H. (2006) Development and Validation of an HPLC/UV/MS Method for Simultaneous Determination of 18 Preservatives in Grapefruit Seed Extract. Journal of Agricultural and Food Chemistry, 54, 3768-3772. https://doi.org/10.1021/jf060543d

[10] Platt, R. (2000) Current Concepts in Optimum Nutrition for Cardiovascular Disease. Preventive Cardiology, 3, 83-87. https://doi.org/10.1111/j.1520-037X.2000.80364.x

[11] Reitman, S. and Frankel, S. (1957) A Colorimetric Method for the Determination of Serum Glutamic Oxaloacetic Acid and Glutamic Pyruvic Transaminases. American Journal of Clinical Pathology, 28, 56-63. https://doi.org/10.1093/ajcp/28.1.56

[12] So, F.V., Guthrie, N., Chambers, A.F., Moussa, M. and Carroll, K.K. (1996) Inhibition of Human Breast Cancer Cell Proliferation and Delay of Mammary Tumorigenesis by Flavonoids and Citrus Juices. Nutrition and Cancer, 26, 167-181. https://doi.org/10.1080/01635589609514473

[13] Miyata, M., Takano, H., Guo, L.Q., Nagata, K. and Yamazoe, Y. (2004) Grapefruit Juice Intake Does Not Enhance But Rather Protects against Aflatoxin B1-Induced Liver DNA Damage through a Reduction in Hepatic CYP3A Activity. Carcinogenesis, 25, 203-209. https://doi.org/10.1093/carcin/bgg194

[14] Sakr, S.A., Zoail, M.E. and El-Shafey, S.S. (2013) Rytmonorm-Induced Cytogenetic and Testicular Damage in Albino Rats: The Protective Effect of Grapefruit Juice. American Journal of Biomedical Research, 1, 1-6. https://doi.org/10.12691/ajbr-1-1-1

[15] Bhalla, P., Chadha, V.D., Dhar, R. and Dhawan, D.K. (2007) Neuroprotective Effects of Zinc on Antioxidant Defense System in Lithium-Treated Rat Brain. Indian Journal of Experimental Biology, 45, 954-958.

[16] Kiernan, J.A. (1981) Histological and Histochemical Methods, Theory and Practice. Pergamon Press, New York, Oxford.

[17] Pearse, A.G.E. (1972) Histochemistry: Theoretical and Applied. 3rd Edition, Vol. 2, Churchill Livingstone, London.

[18] Bancroft, J.D., Stevens, A. and Turner, D.R. (1996) Theory and Practice of Histological Techniques.4th Edition, Churchill Livingstone, New York.

[19] Bouasla, I., Bouasla, A., Boumendjel, A., El Feki, A. and Messarah, M. (2014) Anti- 
oxidant Effect of Alpha Lipoic Acid on Hepatotoxicity Induced by Aluminum Chloride in Rats. International Journal of Pharmaceutical Sciences Review and Research, 29, 19-25.

[20] Zhu, Y., Li, X., Chen, C., Wang, F., Li, J., Hu, C., Li, Y. and Miao, L. (2012) Effects of Aluminum Trichloride on the Trace Elements and Cytokines in the Spleen of Rats. Food and Chemical Toxicology, 50, 2911-2915. https://doi.org/10.1016/j.fct.2012.05.041

[21] Bogdanović, M., Janeva, A.B. and Bulat, P. (2008) Histopathological Changes in Rat Liver after a Single High Dose of Aluminum. Arhiv Za Higijenu Rada I Toksikologiju, 59, 97-101. https://doi.org/10.2478/10004-1254-59-2008-1859

[22] El-Sayed, W.M., Al-Kahtani, M.A. and Abdel-Moneim, A.M. (2011) Prophylactic and Therapeutic Effects of Taurine against Aluminum-Induced Acute Hepatotoxicity in Mice. Journal of Hazardous Materials, 192, 880-886.

https://doi.org/10.1016/j.jhazmat.2011.05.100

[23] Ogueche, P.N., Ugwu, C.E., Ezejindu, D.N., Omeje, M., Dike, C.C., Okonkwo, C.O., Maduka, H.C.C. and Obidoa (2014) Aluminum Intoxication Induced Biochemical and Histopathological Alterations in Male Wistar Albino Rats Hepatocytes. Journal of Natural Sciences Research, 4, 6-12.

[24] Shrivastava, S. (2013) Amelioration of Aluminum-Induced Toxicity by Allium Sativum. Scientific Research and Essays, 8, 168-177.

[25] Newairy, A.S., Salama, A.F., Hussien, H.M. and Yousef, M.I. (2009) Propolis Alleviates Aluminum-Induced Lipid Peroxidation and Biochemical Parameters in Male Rats. Food and Chemical Toxicology, 47, 1093-1098. https://doi.org/10.1016/j.fct.2009.01.032

[26] Tripoli, E., Guardia, M.L., Giammanco, S., Majo, D.D. and Giammanco, M. (2007) Citrus Flavonoids: Molecular Structure, Biological Activity, and Nutritional Properties: A Review. Food Chemistry, 104, 466-479. https://doi.org/10.1016/j.foodchem.2006.11.054

[27] Dua, R., Kumar, V., Sunkaria, A. and Gill, K.D. (2010) Altered Glucose Homeostasis in Response to Aluminum Phosphide Induced Cellular Oxygen Deficit in Rat. Indian Journal of Experimental Biology, 48, 722-730.

[28] Abubakar, M.G., Taylor, A. and Ferns, G.A.A. (2003) Aluminum Administration Is Associated with Enhanced Hepatic Oxidant Stress That May Be Offset by Dietary Vitamin E in the Rat. International Journal of Experimental Pathology, 84, 49-54. https://doi.org/10.1046/j.1365-2613.2003.00244.x

[29] Exley, C. (2001) Aluminum and Alzheimer's Disease. The Science That Describes the Link, Elsevier Science, Amsterdam, New York, 147-168. https://doi.org/10.3233/JAD-2001-3605

[30] Belaid-Nouira, Y., Bakhta, H., Bouaziz, M., Flehi-Slim, I., Haouas, Z. and Ben Cheikh, H. (2012) Study of Lipid Profile and Parieto-Temporal Lipid Peroxidation in $\mathrm{AlCl}_{3}$ Mediated Neurotoxicity Modulatory Effect of Fenugreek Seeds. Lipids in Health and Disease, 11, 16-24. https://doi.org/10.1186/1476-511X-11-16

[31] Kan, W.C., Chien, C.C., Wu, C.C., Su, S.B., Hwang, J.C. and Wang, H.Y. (2010) Comparison of Low-Dose Deferoxamine versus Standard-Dose Deferoxamine for Treatment of Aluminum Overloads among Hemodialysis Patients. Nephrology Dialysis Transplantation, 25, 1604-1608. https://doi.org/10.1093/ndt/gfp649

[32] Shafer, T.J. and Mundy, W.R. (1995) Effects of Aluminum on Neuronal Signal Transduction: Mechanisms Underlying Disruption of Phosphoinositide Hydrolysis. General Pharmacology, 26, 889-895. https://doi.org/10.1016/0306-3623(94)00296-Y 
[33] Martin, K. and Appel, C. (2010) Polyphenols as Dietary Supplements: A Double-Edged Sword. Nutrition and Dietary Supplements, 2, 1-12.

[34] Lee, M.H., Yoon, S. and Moon, J.O. (2004) The Flavonoid Naringenin Inhibits Dimethylnitrosamine-Induced Liver Damage in Rats. Biological and Pharmaceutical Bulletin, 27, 72-76. https://doi.org/10.1248/bpb.27.72

[35] Park, H.J., Jung, U.J., Cho, S.J., Jung, H.K., Shim, S. and Choi, M.S. (2013) Citrus Unshiu Peel Extract Ameliorates Hyperglycemia and Hepatic Steatosis by Altering Inflammation and Hepatic Glucose and Lipid-Regulating Enzymes in db/db Mice. The Journal of Nutritional Biochemistry, 24, 419-427. https://doi.org/10.1016/j.jnutbio.2011.12.009

[36] Golli-Bennour, E.E., Bouslimi, A., Zouaoui, O., Achour, A. and Bacha, H. (2010) Cytotoxicity Effects of Amiodarone on Cultured Cells. Experimental and Toxicologic Pathology, 64, 425-430. https://doi.org/10.1016/j.etp.2010.10.008

[37] Sakr, S.A. and El-Gamal, E.M. (2016) Effect of Grapefruit Juice on Amiodarone-Induced Nephrotoxicity in Albino Rats. Toxicology and Industrial Health, 32, 68-75. https://doi.org/10.1177/0748233713498443

[38] Faid, S.M.A., Fadlalla, E.A.S. and Khojah, E.Y. (2017) Antidiabetic and Antioxidant Effects of Grapefruit, Mango and Strawberry Juice in Streptozotocin-Induced Diabetic Rats. Journal of Applied Life Sciences International, 11, 1-13. https://doi.org/10.9734/JALSI/2017/31960

[39] Alvarez-Gonzalez, I., Madrigal-Bujaidar, E. and Sanchez-Garca, V.Y. (2010) Inhibitory Effect of Grapefruit Juice on the Genotoxic Damage Induced by Ifosfamide in Mouse. Plant Food. HUM Nutrition, 65, 367-373. https://doi.org/10.1007/s11130-010-0193-1

[40] Girennavar, B., Jayaprakasha, G.K., Jadegoud, Y., Nagana Gowda, G.A. and Patil, B.S. (2007) Radical Scavenging and Cytochrome P450 3A4 Inhibitory Activity of Bergaptol and Geranyl Coumarin from Grapefruit. Bioorganic \& Medicinal Chemistry, 15, 3684-3691. https://doi.org/10.1016/j.bmc.2007.03.047

[41] Buchner, I., Medeiros, N., Lacerda, D.S., Normann, C.A., Gemelli, T., Rigon, P., Wannmacher, C.M., Henriques, J.A., Dani, C. and Funchal, C. (2014) Hepatoprotective and Antioxidant Potential of Organic and Conventional Grape Juices in Rats Fed a High-Fat Diet. Antioxidants (Basel), 3, 323-338. https://doi.org/10.3390/antiox3020323

[42] Dani, C., Oliboni, L.S., Umezu, F.M., Pasquali, M.A., Salvador, M., Moreira, J.C. and Henriques, J.A. (2009) Antioxidant and Antigenotoxic Activities of Purple Grapejuice-Organic and Conventional-In Adult Rats. Journal of Medicinal Food, 12, 1111-1118. https://doi.org/10.1089/jmf.2008.0256 